\title{
Aquisição de uma Viatura Blindada Multitarefa Leve sobre Rodas (VBMT-LR) para o Exército Brasileiro por meio do Método Híbrido AHP-TOPSIS-2N
}

\author{
Evanderson Martins (UNIGRANRIO) evandersonmartins@unigranrio.br \\ Douglas Fraga (UNIGRANRIO) douglas.fraga@unigranrio.br \\ Wellington Ávila (IBMR) wellington.avila@ibmr.br
}

Prof. Dr. Marcos dos Santos (Instituto Militar de Engenharia - IME)

marcosdossantos_doutorado_uff@yahoo.com.br

\section{Resumo}

O artigo em questão visa decidir a escolha de um veículo leve blindado multitarefas sobre rodas para o Exército Brasileiro no projeto Guarani. De todos os modelos apresentados foram finalistas na licitação dois veículos, um deles foi o veículo fabricado pela empresa Iveco chamado Lince LMV e outro foi o modelo da Avibrás com parceria com a Renault Truck Defense chamado Tupi. Diante desses dois modelos pergunta-se, qual veículo escolher? Neste artigo utilizou-se o método AHP TOPSIS 2N como método multicritério para indicar qual seria a melhor alternativa. A escolha de um veículo adequado para o EB traz beneficios não só para o mesmo, mas também para a sociedade como todo, pois possibilita que as operações de segurança sejam bem sucedidas e com isso trazendo a diminuição de índices de violência.

Palavras-Chaves: Viatura Blindada Multitarefa Leve (VBML); Método AHP-TOPSIS-2N; Exército Brasileiro.

\section{Introdução}

Com o avanço tecnológico na área militar muitos exércitos ao redor do mundo têm investido pesado em novas tecnologias para estarem preparados na proteção de sua pátria. Foi pensando nisso que o Exército Brasileiro criou o projeto Guarani que faz parte de uma série de mudanças e estruturações da Força. Foram lançados novos blindados do tipo leve sobre rodas no cenário internacional como o Pátria AMV, o Centauro 1l, o Boxer, entre outros, O EB por sua vez criou esse projeto para equiparar suas tecnologias com as internacionais. 
O Brasil já possuía um veículo reconhecido chamado Cascavel que tem um poder de fogo significativo, porém viu-se a necessidade de novos blindados para equiparar sua infantaria com os avanços tecnológicos internacionais. Com isso, o EB em parceria com a empresa Iveco lançou o blindado Guarani, este que daria o nome a todo o projeto de modernização da cavalaria mecanizada militar.

O Guarani é um blindado com capacidade de 11 tripulantes com Torre UT-30BR criada pela AEL Sistemas com canhão automático de $30 \mathrm{~mm}$, porém viu a necessidade de um modelo mais compacto e assim a Iveco laçou um modelo chamado Lince que vem a ser um veículo menos que vem a ser mais acessível nas operações urbanas, e em contra partida a Avibrás também lançou um modelo para concorrer com a Iveco chamado Tupi.

Dada a sua amplitude e o impacto potencial das consequências de suas decisões o contexto militar de decisão vem se tornando cada vez mais importante [Haerem e Kelsen 2011].

A tomada de decisão para a escolha da viatura mais adequada, parte do princípio a identificação de uma oportunidade ou de um problema com o potencial de se aplicar uma ação visando a solução da problemática em questão. Segundo Pereira, Lobler e De Oliveira Simonetto (2010) a teoria da decisão tem sido preponderantemente prescritiva e normativa, pois procura estabelecer regras e modelos que são sugeridos para serem seguidos.

Tendo em vista as características de o ambiente militar, este artigo tem a finalidade de apresentar uma análise sistematizada das alternativas de viaturas blindadas.

\section{Descrição do Problema}

No ano de 2013, o Estado-Maior do Exército (EME) aprovou o Estudo de Viabilidade da Viatura Blindada Multitarefa Leve de Rodas (VBMT-LR), que viria a complementar o Projeto Estratégico do Exército Guarani. A implementação desta nova classe de veículos surgiu devido ao aumento da utilização de Dispositivos Explosivos Improvisados (IED), implicando inviabilidade no uso de viaturas leves com baixa ou inexistente blindagem (como a Marruá) para determinadas missões - especialmente em ambientes urbanos.

O EPEX divulgou uma lista de requisitos técnicos, que englobam dimensões, desempenho, proteção balística anti-minas nível 2 e sistema de armas. 
Praticamente todas as grandes montadoras mundiais têm viaturas que atenderiam os requisitos técnicos. Propostas foram entregues pela IVECO Latin America contendo ofertas de seus Veículos Multifuncionais Leves (LMV conforme sigla em inglês), pela Avibras envolvendo o Tupi (versão brasileira do Sherpa da Renault Trucks Defense), pela BAE Systems Land Systems South África ofertando o RGvibr32M LTV e pela AM General and Plasan propondo o MLTV-BR. Entretanto, as finalistas do programa foram a Iveco, oferecendo seu Lince LMV e Avibrás em parceria com a Renault Truck Defense oferecendo o Tupi. As figuras 1 e 2 apresentam os modelos da IVECO e da Avibrás, respectivamente.

Figura 1: Iveco Lince

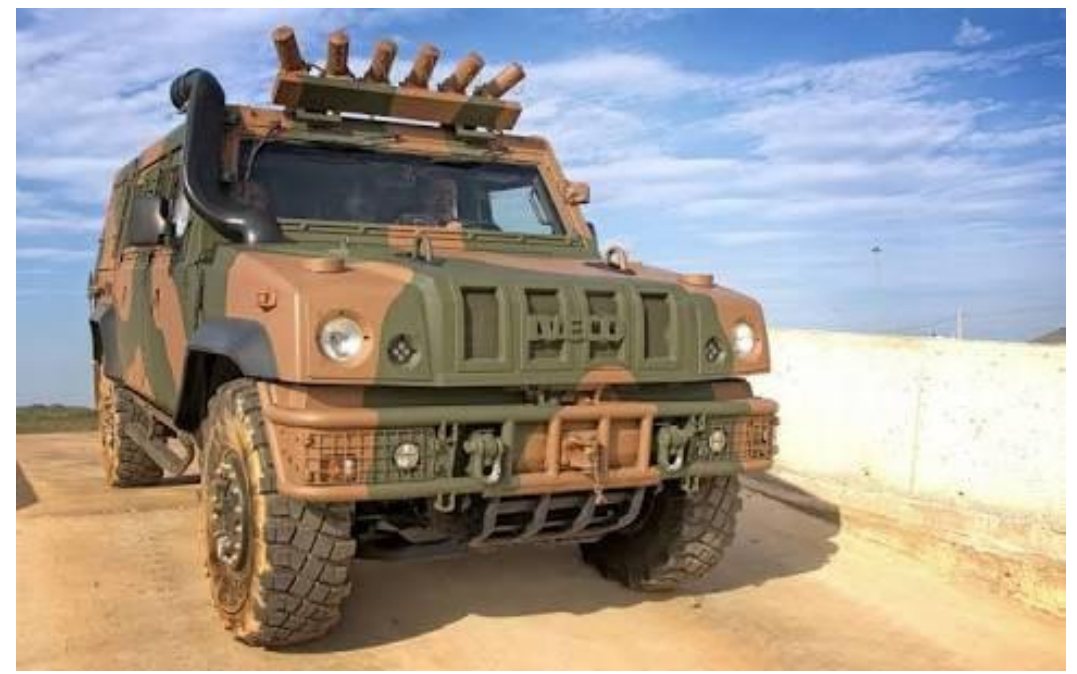

Fonte: IVECO (2019) 


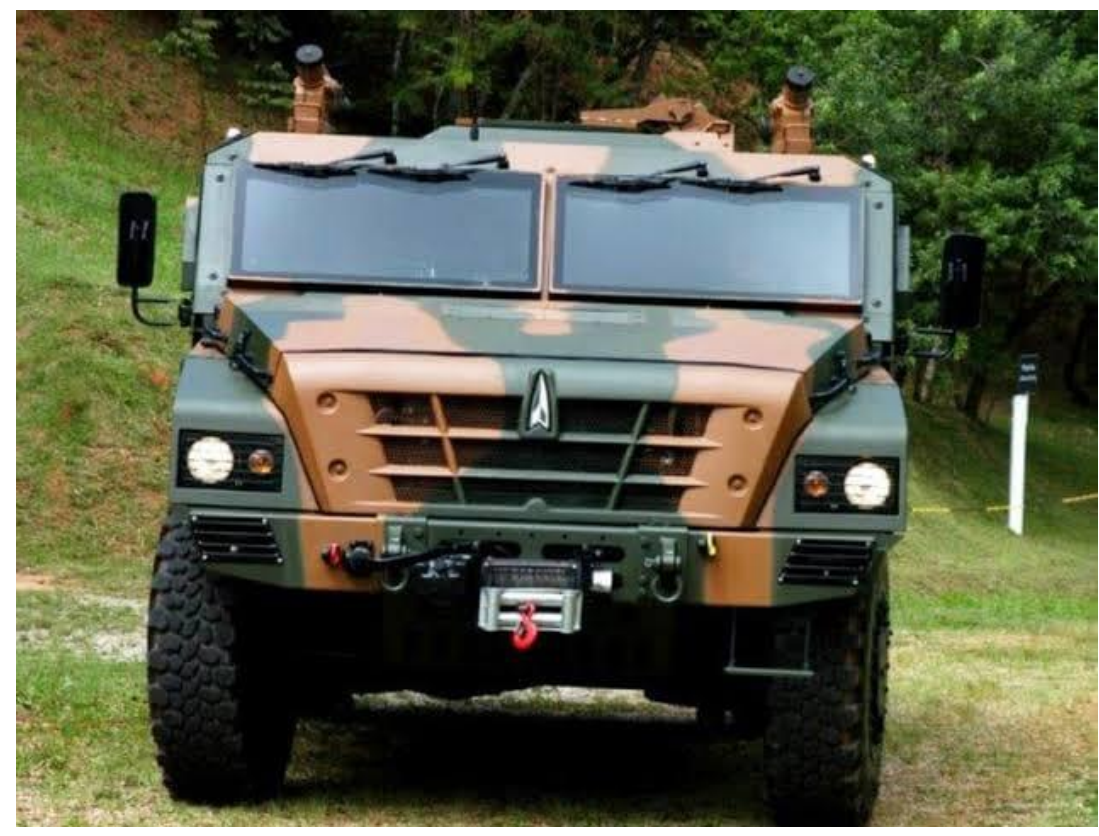

Fonte: Avibrás (2019)

Diante deste cenário, surge o questionamento de qual seria a melhor opção de veículo a ser adquirido pelo EB? Transformando a cavalaria motorizada em mecanizada, e ainda modernizar a cavalaria mecanizada. Para resposta deste questionamento, o método híbrido de apoio à decisão multicritério AHP-TOPSIS-2N foi escolhido visando elucidar o julgamento para uma avaliação das opções. O método AHP, mostra-se um método de ponderação de critérios e criação de ranking de preferências. Conforme afirmado por Ribeiro, Passos e Teixeira (2013) na década de 70 Thomas L. Saaty desenvolveu o Método de Análise Hierárquica. Por organizar critérios de forma hierárquica de maneira no qual o problema decisório assume a posição do topo da hierarquia o seu nome original em inglês é Analytic Hierarchy Process (AHP). Os critérios definidos por especialistas são analisados e comparados paritariamente (Saaty, 1990). O método TOPSIS baseia-se no conceito de que a melhor alternativa deve ter a menor distância de uma solução ideal e a maior distância da solução não ideal

Para melhorar o entendimento e delimitar as condições do contorno do problema, foi construído um mapa mental, o qual consta na Figura 3. 


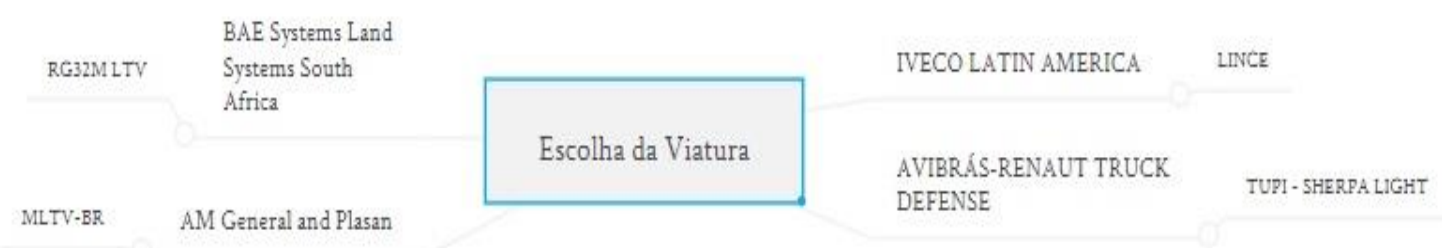

Fonte: Autores (2019)

\section{Fundamentação Teórica}

Atualmente existem diversos métodos de apoio a tomada de decisão. De acordo com Azevedo, Ferreira e Silva (2018), os métodos de Apoio Multicritério à Decisão têm um caráter cientifico e, ao mesmo tempo, apresenta capacidade de agregar todas as características consideradas importantes, inclusive as não quantitativas. Tais métodos possuem foco diferenciado dos problemas e passam a atuar sob a forma de auxílio à decisão. Em um cenário cada vez mais dinâmico e competitivo, com decisões embasadas em multicritérios, sendo peculiar por sua alta complexidade e diversidade de alternativas surge essa necessidade.

O processo de escolha da melhor alternativa de viatura envolve uma diversidade de critérios, complexos entre si. Nestas situações, é intrínseco do ser humano o desejo de alcançar seus objetivos em detrimento dos objetivos grupais (MORAIS e FONTANA, 2019).

É possível chegar à tomada de decisão eficaz após uma análise minuciosa de dados, informações e conhecimentos que envolvem fatores criteriosos críticos das viaturas em questão que circulam internamente e externamente à organização por meio de um canal de comunicação adequado e com uma infraestrutura tecnológica confiável. A produção interna da informação e a utilização de fontes externas à organização suscitam a criação de sistemas de informação para sua identificação e organização, propiciando condições mais adequadas para sua recuperação e utilização na tomada de decisão (GUIMARÃES e ÉVORA, 2004).

Como prática militar, oriunda nas sociedades da antiguidade, a Inteligência Competitiva fortalece a tomada de decisão nas organizações e influencia na competitividade do mercado, estando também presente inclusive no mundo corporativo (PINTRO; VIANNA e VARVAKIS, 2016). 
Métodos de apoio a decisão multicritério são utilizados quando há a necessidade de selecionar, ordenar, classificar ou descrever alternativas presentes em processo decisório complexo com múltiplos critérios e objetivos em conflito (SOUZA et. al., 2016).

\subsection{Método AHP TOPSIS 2N}

Segundo Colombo, Santos e Gomes (2019) o método AHP-TOPSIS-2N é um método híbrido constituído por duas técnicas de tomada de decisão multicritério que são usualmente adotadas em cenários complexos, caracterizados pela presença de objetivos múltiplos e conflitantes. Para entender o método é inerente um prévio entendimento das duas técnicas que o compõe.

\subsection{Método AHP}

Por ser um método simples, que permite comparações paritárias e baseia-se em julgamentos de especialistas para derivar escalas de prioridade, têm sido amplamente aplicado por pesquisadores e tomadores de decisão (Vaidya e Kumar, 2006).

Segundo Gomes (2009), o AHP é baseado na comparação paritária dos critérios, buscando responder duas perguntas principais: Quais são os critérios de maior importância e qual a proporção dessa importância.

Para tais questões os decisores devem atribuir pesos numa escala de 1 a 9 para cada critério, e os comparando par a par (BERZINS, 2009). Cabe destacar que este método somente pode ser utilizado quando os parâmetros forem passíveis ter sua importância mensurada numa escala de quociente ou razão. Os passos do método AHP encontram-se detalhados na Figura 4. 


\begin{tabular}{|c|c|c|c|}
\hline \multicolumn{4}{|c|}{ Resumo do Método AHP segundo Saaty } \\
\hline Ordem & $N^{2}$ Eq. & Equação & Descrição da Equação \\
\hline 12 Passo & Eq. 1 & 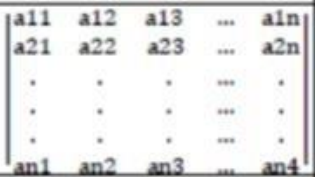 & $\begin{array}{l}\text { Formação das matrizes de decisão. Expressa o } \\
\text { número de vezes em que uma alternativa } \\
\text { domina ou é dominada pelas demais (ARAYA, } \\
\text { CARIGNANO e GOMES, 2004). }\end{array}$ \\
\hline 29 Passo & Eq. 2 & $w_{i}=\left(\prod_{i=1}^{\mathrm{n}} w_{i j}\right)^{1 / \mathrm{n}}$ & $\begin{array}{l}\text { Cálculo do Autovetor (Wi). Consiste em } \\
\text { ordenar as prioridades ou hierarquias das } \\
\text { caracteristicas estudadas (COSTA, 2006). }\end{array}$ \\
\hline 32 Passo & Eq. 3 & $\tau=\left|\frac{w_{1}}{\Sigma W_{i}}: \frac{w_{2}}{\Sigma W_{i}}: \frac{w_{3}}{\Sigma W_{i}}\right|$ & $\begin{array}{l}\text { Cálculo de Normalização dos autovetores } \\
\text { possibilita a comparabilidade entre os critérios } \\
\text { e alternativas (COSTA, 2006). }\end{array}$ \\
\hline $4 \%$ Passo & Eq. 4 & $\lambda \max =\mathrm{T} \times \mathrm{W}$ & $\begin{array}{l}\text { Indice que relaciona os critérios da Matriz de } \\
\text { Consistência e os pesos dos critérios (COSTA, } \\
\text { 2006). }\end{array}$ \\
\hline 52 Passo & Eq. 5 & $I C=\frac{\lambda m a ́ x .-n}{(n-1)}$ & $\begin{array}{l}\text { İndice de Consistência (IC). Permite avaliar o } \\
\text { grau de inconsistência da matriz de } \\
\text { julgamentos pariados (COSTA, 2006). }\end{array}$ \\
\hline 69 Passo & Eq. 6 & $R C=\frac{I C}{C A}$ & $\begin{array}{l}\text { Razão de Consistência (RC). Permite avaliar a } \\
\text { inconsistência em função da ordem da matriz } \\
\text { de julgamentos. Caso o valor seja maior que } \\
0,10 \text { revisar o modelo e/ou os julgamentos } \\
\text { (COSTA, 2006). }\end{array}$ \\
\hline
\end{tabular}

Fonte: Mendes et al. (2013)

A Figura 5 apresenta de maneira esquemática o passo a passo para a aplicação do método:

Figura 5: Passo a passo para aplicação do método AHP.

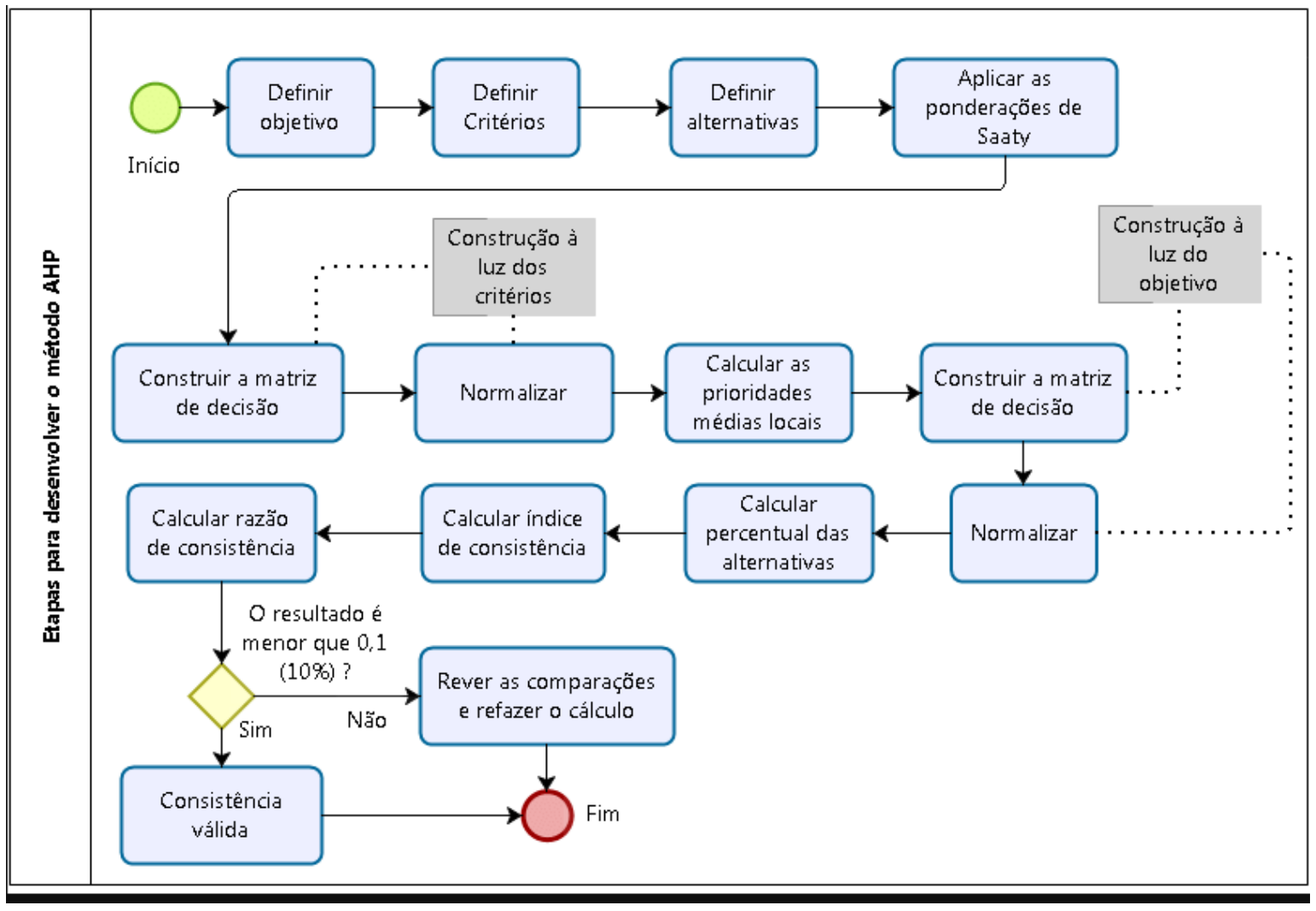

Fonte: Souza et al. (2019)

\subsection{Método TOPSIS}


O Método TOPSIS (do inglês Technique for Order Preferences by Similarity to Ideal Solution) é uma técnica para MCDM para ordenamento de preferência por similaridade pela solução ideal que foi apresentada por Hwang e Yoon em 1981 (HWANG e YOON, 1981). Com o propósito de solucionar um problema de tomada de decisões com múltiplos atributos. Parte do princípio de que a melhor alternativa a ser escolhida deve estar na menor distância da solução ideal positiva (SIP) e da maior distância da solução ideal negativa (SIN). Para Olson (2004); Barros e Wanke (2015) o método baseia-se nas seguintes etapas:

$1^{\circ}$. Construção da matriz de decisão;

$2^{\circ}$. Normalização da matriz de decisão;

$3^{\circ}$. Ponderação dos critérios da matriz de decisão;

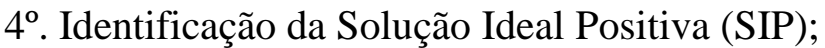

$5^{\circ}$. Identificação da Solução Ideal Negativa (SIN);

$6^{\circ}$. Cálculo da distância euclidiana de cada alternativa para a SIN e para a SIP;

$7^{\circ}$. Obtenção do ranking da melhor alternativa para a pior alternativa.

\section{Proposta de Solução a partir do Método AHP-TOPSIS-2N}

Desenvolveu-se um estudo para a escolha da melhor alternativa de veículos a luz da aplicação das técnicas de apoio à decisão. Nesta pesquisa foram avaliadas duas alternativas de veículos blindados leves para compor o Programa Guarani do Exército Brasileiro. Os critérios do modelo foram baseados na lista de requisitos técnicos divulgados pelo EPEX. São eles: altura, peso, largura, velocidade máxima, autonomia, proteção balística, proteção antiminas, sistema de armas, capacidade de transporte pessoal e capacidade de carga. A matriz de decisão foi construída e apresentada na Tabela 1. 
Tabela 1: Matriz de decisão

$\begin{array}{lllllllllll}\text { Alternativas } & \text { C1 } & \text { C2 } & \text { C3 } & \text { C4 } & \text { C5 } & \text { C6 } & \text { C7 } & \text { C8 } & \text { C9 } & \text { C10 } \\ \text { LINCE } & 1,95 & 6500 & 2,05 & 130 & 500 & 7,62 & 2 & 7,62 & 5 & 1200 \\ \text { TUPI } & 2,1 & 8000 & 2,2 & 100 & 800 & 7,62 & 3 & 50 & 6 & 2500\end{array}$

Fonte: Autores (2019)

Os resultados do método AHP TOPSIS 2N foram obtidos a partir de um software desenvolvido em Python por Ribeiro, Santos e Gomes (2019), no Instituto Militar de Engenharia. No software foram lançados os dados da matriz de ponderações, conforme a Figura 6.

Figura 6: Matriz de Ponderações

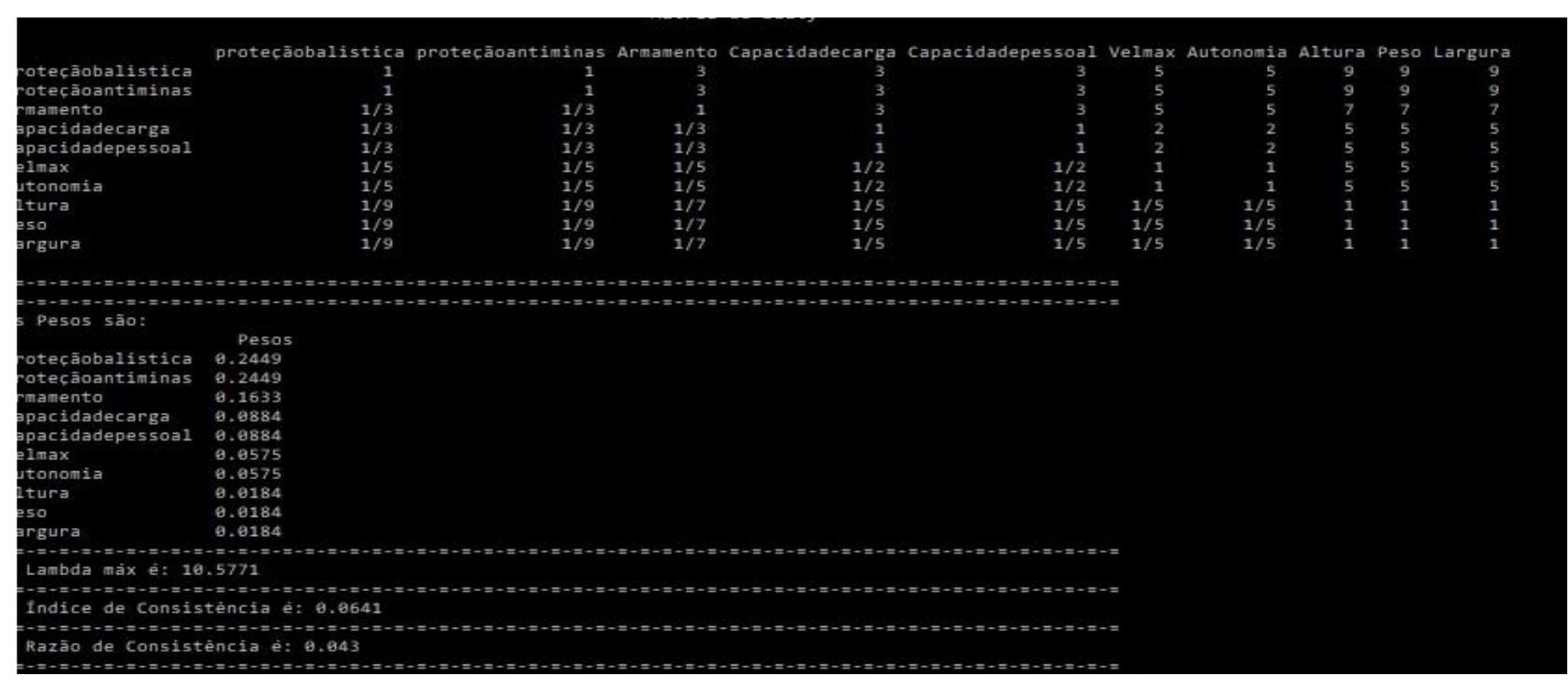

Fonte: Autores (2019)

Também pode se observar na Figura 6, que a matriz de ponderações gerou um peso para cada um dos critérios. Para melhor visualização e entendimento, estes dados constam na Tabela 2. 
Tabela 2: Pesos dos critérios

\begin{tabular}{|lrrr|}
\hline Proteção balistica & 0,2449 & Razão da Consistência & $\mathbf{0 , 0 4 3}$ \\
\hline $\begin{array}{l}\text { Proteção } \\
\text { Antiminas }\end{array}$ & 0,2449 & Lambda Max & $\mathbf{1 0 , 5 7 7 1}$ \\
\hline Armamento & 0,1633 & Índice de Consistência & $\mathbf{0 , 0 6 4 1}$ \\
\hline $\begin{array}{l}\text { Velocidade } \\
\text { máxima }\end{array}$ & 0,0884 & & \\
\hline Autonomia & 0,0884 & & \\
\hline $\begin{array}{l}\text { Capacidade } \\
\text { Pessoal }\end{array}$ & 0,0575 & \\
\hline Capacidade Carga & 0,575 & \\
\hline Peso & 0,0184 & \\
\hline Altura & 0,0184 & \\
\hline Largura & 0,0184 & \\
\hline
\end{tabular}

Fonte: Autores (2019)

Como a razão da consistência foi menor que 0,1 conclui-se que a matriz de ponderações é suficientemente consistente. A próxima etapa é a normalização da matriz de decisão, que e é feita de duas maneiras distintas, conforme apresentado nas Figuras 7 e 8.

Figura 7: Matriz de Decisão e a $1^{\mathrm{a}}$ normalização

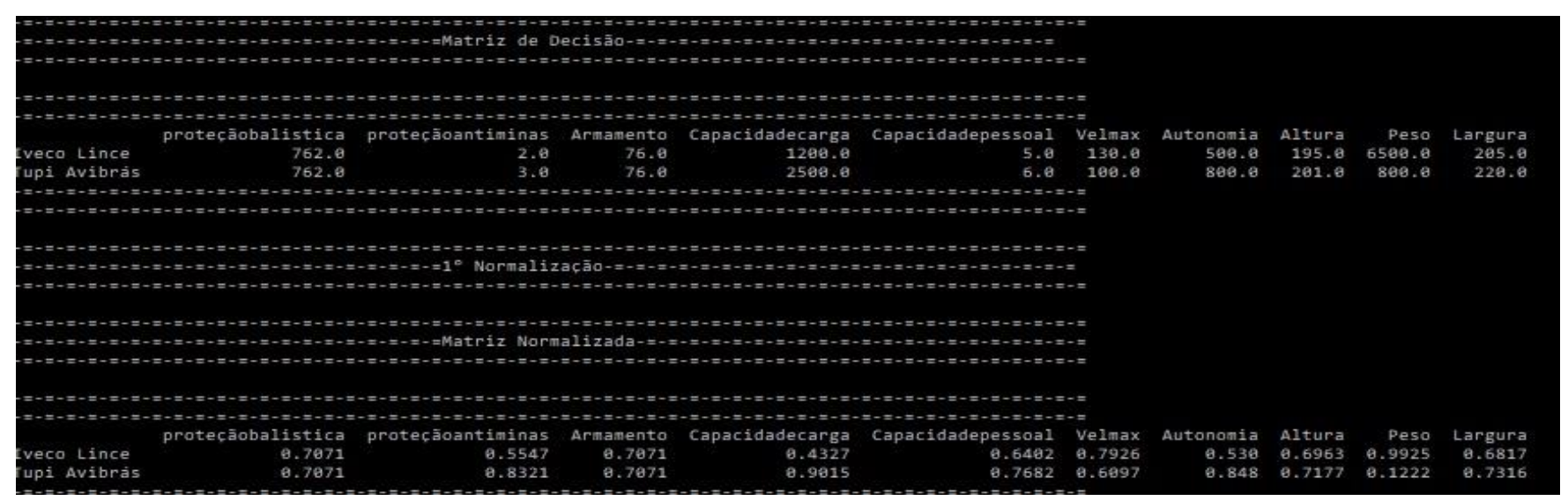

Fonte: Autores (2019) 
Figura 8: Matriz de Decisão com a $1^{\mathrm{a}}$ normalização e ponderada

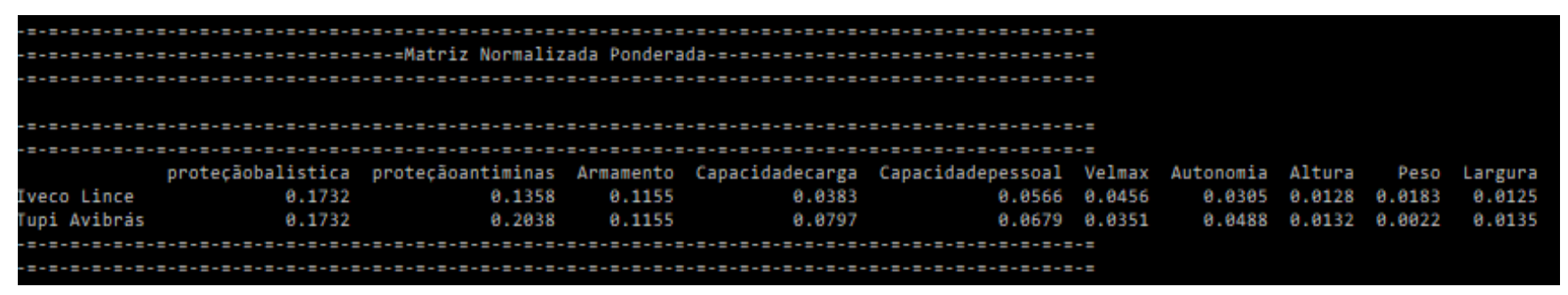

Fonte: Autores (2019)

As Figuras 9 e 10 apresentam os resultados oriundos do $2^{\circ}$ processo de normalização.

Figura 9: $2^{\mathrm{a}}$ Normalização da Matriz de Decisão

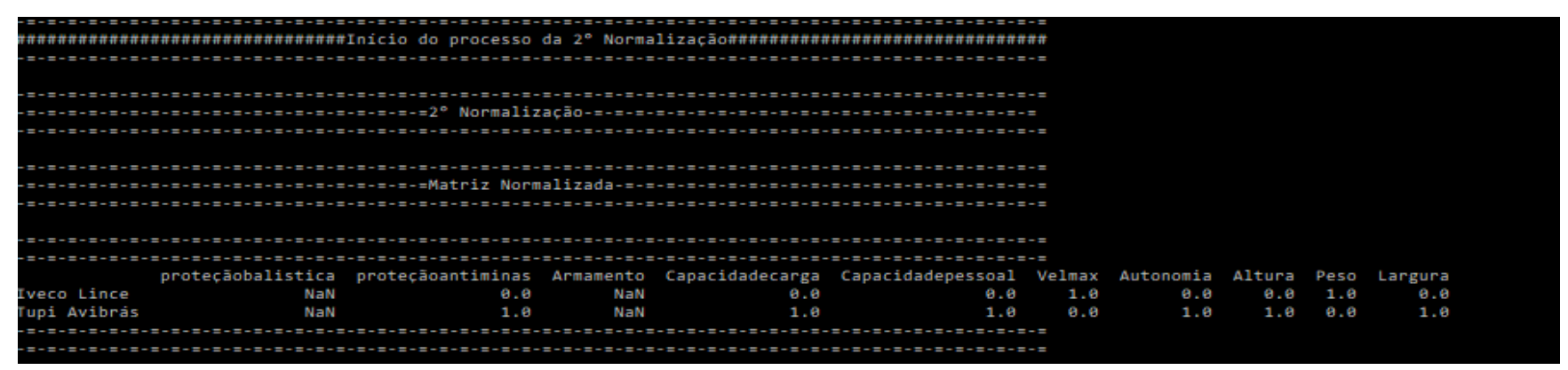

Fonte: Autores (2019)

Figura 10: Matriz de Decisão com a $2^{\mathrm{a}}$ normalização e ponderada

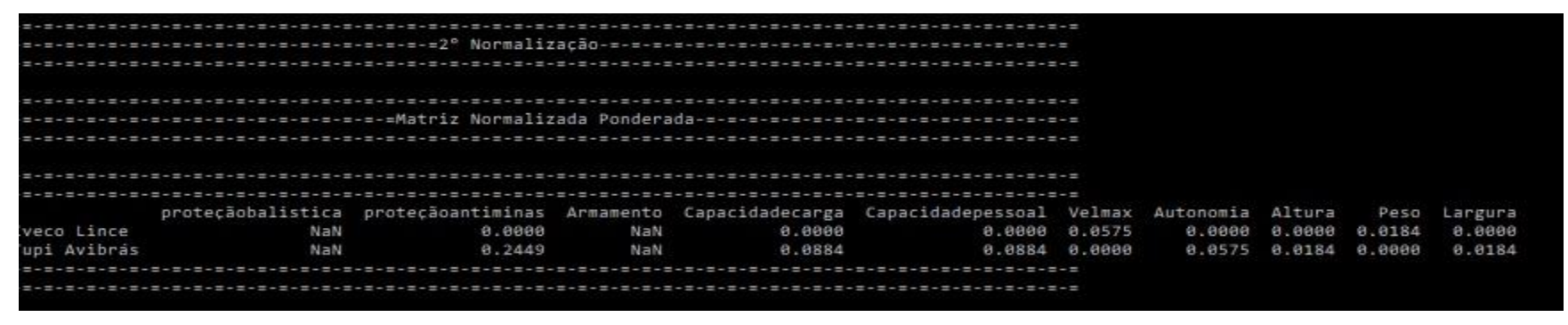

Fonte: Autores (2019)

O próximo passo é a determinação da Solução Ideal Positiva (SIP) e da Solução Ideal Negativa (SIN). Os critérios são classificados em dois tipos: Critérios de custo (quanto menor o rating melhor) e critérios de beneficio (quanto maior o rating melhor). No estudo realizado, a maioria dos critérios é de beneficio, com exceção para peso e largura, conforme apresenta a Figura 11. 
Figura 11 - Solução Ideal

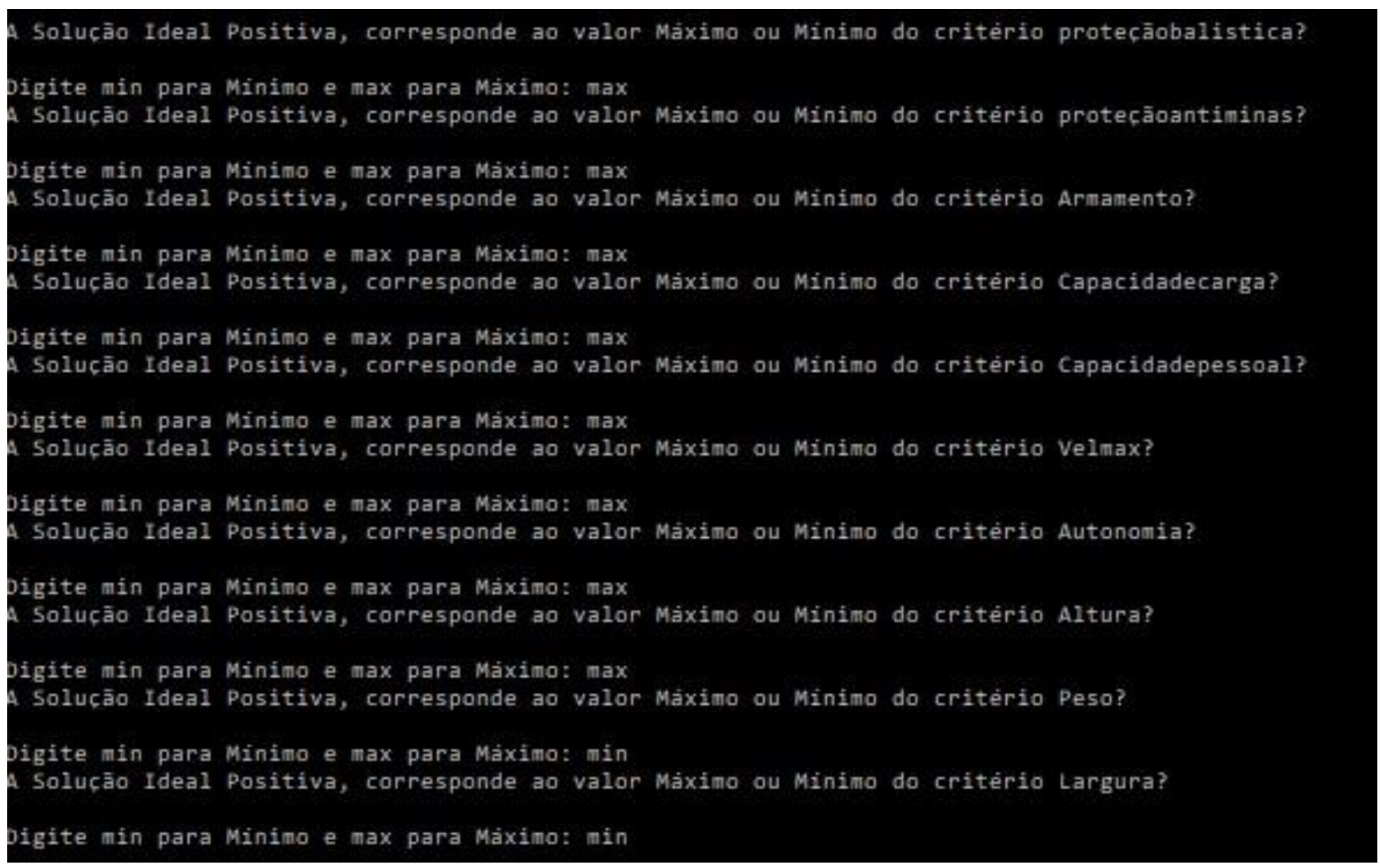

Fonte: Autores (2019)

O último passo é o ranqueamento das alternativas. A melhor alternativa é aquela que tiver o maior valor, porque estará mais próxima da SIP e mais distante da SIN.

Figura 12: Ranqueamento das Alternativas

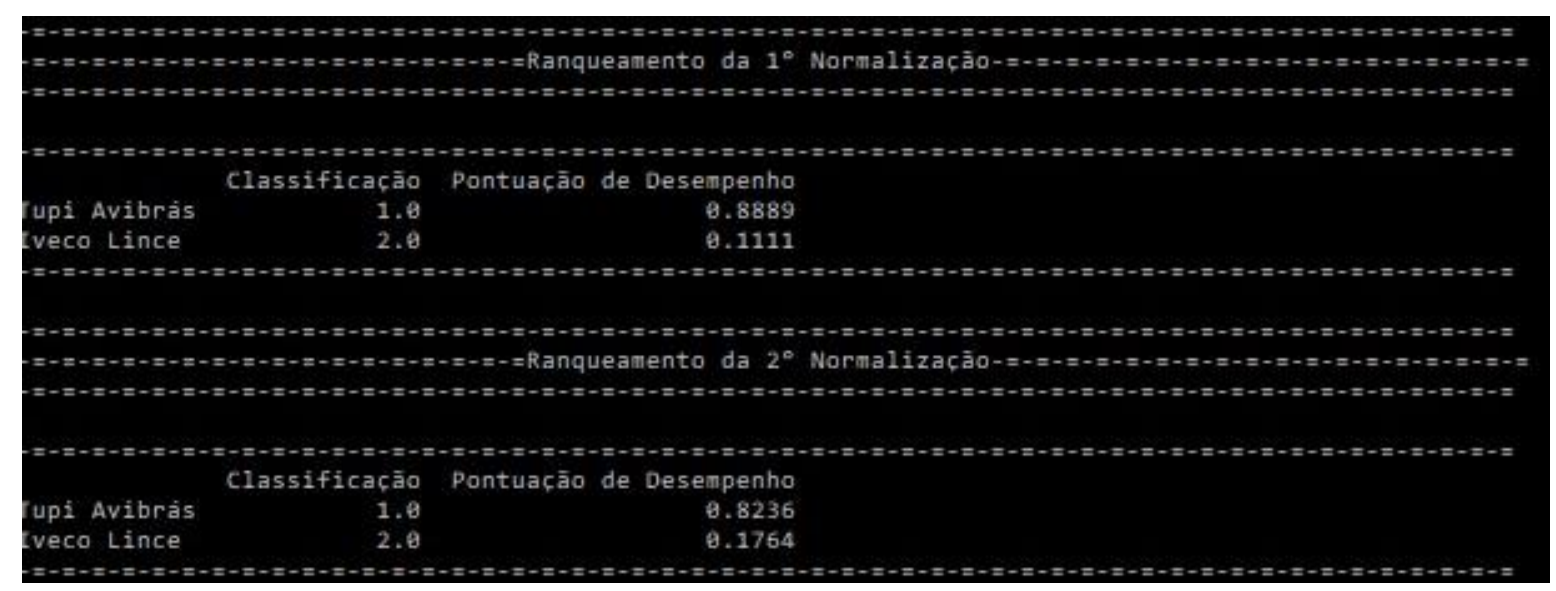

Fonte: Autores (2019) 


\section{Conclusão}

A escolha de qual viatura blindada leve sobre rodas o Exército Brasileiro deve adotar é uma decisão estratégica e complexa. Em um problema de decisão em que envolve múltiplos critérios, o método híbrido de apoio a decisão AHP TOPSIS $2 \mathrm{~N}$ mostrou-se eficiente na indicação da melhor alternativa de veículo leve blindado a ser escolhido.

O modelo da Avibrás em parceria com a Renault Truck Defense mostrou-se amplamente superior a outra alternativa, o Iveco Lince. Entretanto o Exército Brasileiro preferiu escolher o modelo da Iveco.

\section{Referências}

BERZINS, Lorena Jacobson. Avaliação de Desempenho pelo AHP, através do superdecisions; Caso Inmetro. Rio de Janeiro: Faculdades IBMEC. Dissertação de Mestrado Profissionalizante apresentada ao Programa de PósGraduação em Administração das Faculdades IBMEC, 2009.

COLOMBO, Danilo; SANTOS, Marcos dos; GOMES, Carlos Francisco Simões. Seleção da Melhor Configuração de Poço de Petróleo para o Desenvolvimento de um Campo Utilizando o Método AHP TOPSIS 2N. Anais do XIX Simpósio de Pesquisa Operacional e Logística da Marinha, 2019.

EPEX. Nova família de blindados sobre rodas - Programa Guarani. Disponível em:<http://www.epex.eb.mil.br/index.php/guarani>. Acesso em 17 outubro, 2019.

GOMES, L. F. A. M.; ARAYA, M. C. G.; CARIGNANO, C. Tomada de decisão em cenários complexos. São Paulo: Pioneira Thomson Learning, 2009.

GOMES, Luiz Flavio Autran Monteiro. Teoria da Decisão, São Paulo, 2007.

GUIMARÃES, Eliane Marina Palhares; ÉVORA, Yolanda Dora Martinez. Sistema de informação: instrumento para tomada de decisão no exercício da gerência. Ciência da informação, v. 33, n. 1, 2004.

HAEREM, T.; KARLSEN, T. (2011). Do Military Decision Makers Behave as Predicted by Prospect Theory? Journal of Behavioral Decision Making, v. 497, p. 482-497.

HWANG, C. L.; YOON, K. (1981). Multiple Attribute Decision Making Methods and Applications. Springer. Verlag, Berlin.

MENDES, L. F. R.; ERTHAL JÚNIOR, M.; HOSKEN, L. A. L. Seleção de sistema de fornecimento de energia elétrica para propriedades rurais litorâneas localizadas no norte do estado do Rio de Janeiro. Revista eletrônica Produção \& Engenharia, v. 4, n. 1, p. 338-345, 2013

OLSON, D. L. (2004). Comparison of Weights in TOPSIS Models. Mathematical and Computer Modelling. Vol. 40, p.721-727

PEREIRA, Breno A. Diniz; LOBLER, Mauri Leodir; DE OLIVEIRA SIMONETTO, Eugênio. Análise dos modelos de tomada decisão sob o enfoque cognitivo. Revista de Administração da Universidade Federal de Santa Maria, v. 3, n. 2, p. 260-268, 2010.

PINTRO, Sirlene; VIANNA, William Barbosa; VARVAKIS, Gregório. Inteligência Competitiva e Ciência da Informação: conexões epistemológicas para tomada de decisão nas organizações. Em Questão, v. 22, n. 3, p. 10 $35,2016$. 
RIBEIRO, Livia de Souza; PASSOS, Anderson Campos; TEIXEIRA, Marcelo Goulart. Seleção de tecnologias de comunicações no exército brasileiro utilizando os métodos multicritério de análise hierárquica, TODIM e software Sapiens. Production, v. 22, n. 1, p. 132-141, 2013.

RIBEIRO, Wallace Lima; SANTOS, Marcos dos; GOMES, Carlos Francisco Simões. AHP-TOPSIS-2N Software (v.1). Desenvolvido por meio de uma parceria entre o Instituto Militar de Engenharia (IME), o Centro de Análises de Sistemas Navais (CASNAV) e a Universidade Federal Fluminense (UFF), 2019.

SAATY, T. L. (1980) The Analytic Hierarchy Process. New York: McGraw-Hill.

SAATY, T. L. (1990). How to make a decision: the analytic hierarchy process. European Journal of Operational Research, 48:1, 9-26.

SOUZA, Deivison; SANTOS, Marcos dos; WALKER, Rubens Aguiar; REIS, Marcone Freitas dos. Avaliação ergonômica em uma multinacional a partir do método AHP, 2019.

TecnoDefesa. Exército Brasileiro conclui processo para obtenção de viaturas leves $\mathbf{4 \times 4}$. Disponível em:< http://tecnodefesa.com.br/exercito-brasileiro-conclui-processo-para-obtencao-de-viaturas-leves-4x4/>. Acesso em 01 Novembro, 2019

VAIDYA, O. S.; KUMAR, S. (2006) Analytic Hierarchy Process: An overview of applications. European Journal of Operational Research, 169. p.1-29 